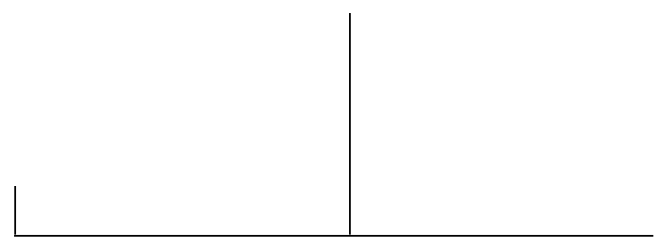

Rev. Latinoam. Psicopat. Fund., São Paulo, v. 13, n. 2, p. 224-237, junho 2010

\title{
Do ideal ascético ao ideal estético: a evolução histórica da Anorexia Nervosa*
}

Cybelle Weinberg

O estudo da anorexia nervosa sob uma perspectiva histórica visa contribuir para a investigação daquilo que se configura como influência cultural na gênese e manutenção do quadro, além de questionar posições segundo as quais a anorexia nervosa seria um "mal da modernidade" ou decorrente de um único fator. Uma análise da vida das santas da Idade Média, por exemplo, mostra quanto o comportamento perseverante as aproxima das anoréxicas de hoje, ainda que a motivação e os ideais (ascético nas primeiras e estético nas últimas) sejam diferentes.

Palavras-chave: Anorexia santa, anorexia nervosa, jejum, cultura

* Resumo da dissertação de mestrado apresentada na Faculdade de Medicina da Universidade de São Paulo - FMUSP (São Paulo, SP, Brasil) em 2004, sob o título Avaliação crítica da evolução histórica do conceito de Anorexia Nervosa e no II Congresso Internacional de Psicopatologia Fundamental e VIII Congresso Brasileiro de Psicopatologia Fundamental, realizados em Belém (PA), Brasil, em 2006. 


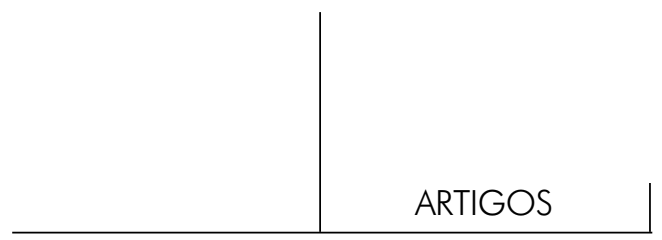

\section{Introdução}

Tida como "doença da modernidade", a Anorexia Nervosa suscita, nas atuais discussões psiquiátricas, a questão clássica sobre as relações entre a doença e a cultura, ou seja, sobre aquilo que se associa a uma característica mórbida invariável - o patogenético - e o que é acessório e influência da cultura - o patoplástico (Cordás; Claudino, 2002).

A existência de transtornos alimentares em outros séculos e culturas, antes dos relatos de Morton (1689), Gull (1868) e Lasègue (1874), é de grande interesse psicopatológico, na medida em que torna relativa a influência da modernidade, muitas vezes colocada como fator causal principal ou até mesmo único.

$\mathrm{O}$ fato de a Anorexia Nervosa permanecer como um enigma e motivo de discussão entre posições biomédicas, psicodinâmicas e culturais levou-nos a fazer uma revisão crítica da literatura existente a respeito da Anorexia Nervosa e, a partir dessa revisão, contextualizar, histórica e culturalmente, as idéias propostas sobre esse transtorno nas diferentes épocas. Esta discussão vai ao encontro da posição de Berrios (1999) para quem todas as classificações psiquiátricas são produtos culturais, funcionando como molduras fornecidas por uma época para uma desordem mental.

\section{Uma história do jejum}

O jejum autoimposto não significa, necessariamente, um transtorno alimentar e tem uma longa história na vida da humanidade. Sabe-se que vários povos da Antiguidade incentivavam o jejum voluntário como uma prática religiosa e viam na abstinência alimentar uma forma de purificação. O jejum prolongado, às vezes até à morte, como parte de um total afastamento do mundo material, era prática comum nas religiões e filosofias orientais. 


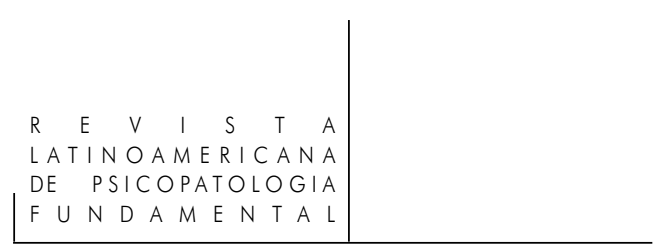

Entre os gregos, o jejum era uma prática curativa e tinha recomendação médica. Hipócrates (460 a.C.-370 a.C), por exemplo, costumava receitar jejuns, vômitos e enemas para o tratamento de quase todas as doenças. A própria palavra ascese (do grego askesis) designava, originalmente, os exercícios físicos dos atletas, acompanhados de rigorosa dieta como preparo para as competições. Somente muitos anos mais tarde o ascetismo passou a designar o que está ligado à virtude, em detrimento do corpo; uma forma de autodisciplina e autopunição com um ideal de completa independência das necessidades físicas, alcançado por meio de jejuns, abstinência sexual, privação de sono, autoflagelação e muitas outras formas de tortura.

$\mathrm{O}$ ascetismo tomou sua forma mais rigorosa no século IV, no Egito, com os "pais do deserto" - homens que abandonavam o mundo civilizado para se dedicar à meditação - e no período medieval, com as santas jejuadoras. A tradição ascética expressa nos primeiros séculos do cristianismo falava tanto a homens como a mulheres e sua característica mais marcante era a defesa da virgindade ou da castidade. Neste contexto começaram a se apresentar as santas jejuadoras, que tiveram maior expressividade nos séculos XIII e XIV, período em que ocorreu uma verdadeira "epidemia do comportamento anoréxico", segundo Fendrik (1997).

\section{As santas jejuadoras}

Santa Vilgefortis (do latim virgo fortis, virgem forte) viveu provavelmente na região correspondente hoje a Portugal, entre os séculos VIII e X. Seu pai, um tirano pagão, conhecido por sua crueldade e rudeza, decidiu casá-la com o rei sarraceno da Sicília. Vilgefortis ficou horrorizada quando soube desses planos, especialmente porque, nessa época, já havia feito voto de castidade. Para preservar sua virgindade e escapar do casamento, rogou intensamente a Deus para ajudá-la, ao mesmo tempo em que iniciava um rigoroso jejum. Conta-se que ela pedia a Deus, em suas orações, que apagasse sua beleza e que foi atendida, com o surgimento de pêlos em seu corpo e crescimento de uma barba. O rei da Sicília, assustado diante de tamanha magreza, desistiu do casamento e seu pai, encolerizado, mandou crucificá-la (Lacey, 1982).

Segundo Radi (1996), Santa Clara de Assis (1193-1253), desde pequena, teria manifestado grande fé religiosa. Na adolescência, foi atraída pelas pregações de Francisco (futuro São Francisco de Assis), a quem decidiu seguir. Francisco obteve para ela o pequeno convento anexo à igreja de São Damião, onde Clara permaneceu até morrer, em 1253. Sem nunca ter deixado o mosteiro, dedicou-se ali à caridade e ao trabalho, sempre incansável em suas tarefas. Apesar de ter esta- 


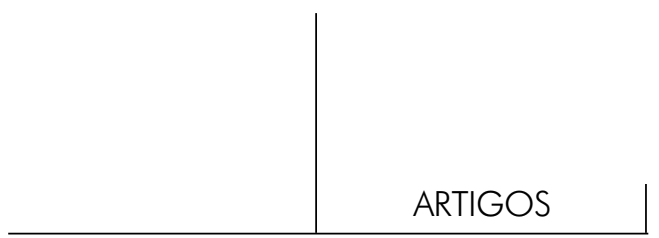

do doente por 28 anos, e seguramente devido às privações - jejuns e penitências -, refere-se a si mesma como "sã e forte", autorizando-se a jejuar todos os dias. Esse tipo de comportamento nos remete às jovens anoréxicas, que incitam os outros a se cuidarem enquanto se impõem mortificações, ao mesmo tempo em que não se vêem como doentes. Some-se a isto a teimosia, o rigor e a intransigência consigo mesma, a hiperatividade e o desejo de reclusão e teremos um quadro que se assemelha em muito à Anorexia Nervosa atual.

Inteligente e precoce, Santa Catarina de Siena (1347-1380) foi uma criança amada, admirada e mimada por todos. Dos 12 aos 16 anos viveu reclusa em seu quarto, rezando à luz de velas, conversando com os familiares o estritamente necessário e saindo de casa apenas para ir à igreja. Mais tarde, iniciado seu período de jejuns, comia somente um pouco de pão e ervas cruas, muitas vezes deixando mesmo de fazê-lo e recorrendo aos vômitos quando forçada a comer. Reduziu seu sono até chegar a dormir por uma hora a cada dois dias, usava o cilício e flagelava seu corpo três vezes ao dia com uma corrente de ferro. Sua dieta era tão preocupante que seu confessor viu-se obrigado a ordenar-lhe que comesse pelo menos uma vez ao dia. Com vinte anos Catarina deixou sua reclusão espontânea e voltou a inserir-se na vida da família e da cidade. Cuidava dos pobres e enfermos e dava esmolas volumosas, que retirava da casa paterna. Ao mesmo tempo atirou-se a uma febril atividade, dedicando-se totalmente à ação político-religiosa que fez sua reputação: a reforma da Igreja. O exagero de suas privações - seu primeiro jejum extraordinário estendeu-se desde a Quaresma até a Ascensão, ou seja, dois meses e meio - fez suspeitar da presença do diabo. Apesar de não tomar nenhum alimento ou bebida, Catarina continuava muito ativa. Raimbault; Eliacheff (1991), Bidaud (1998) e Fendrik (1997) concordam em definir o comportamento de Catarina de Siena, caracterizado pelo jejum prolongado, hiperatividade, despotismo e mortificação do corpo, como típico das anoréxicas atuais. Esta santa, provavelmente pela rigidez de seu ascetismo, entre outras razões, foi escolhida por outras tantas santas e beatas como modelo. Santa Madalena de Pazzi e Santa Rosa de Lima são os melhores exemplos de suas seguidoras.

Nascida em Florença em 2 de abril de 1566, Santa Maria Magdalena de Pazzi (1566-1670) ingressou no convento aos 16 anos e ao receber os votos, um ano depois, trocou seu nome de batismo, Caterina, por Maria Madalena. Aos 19 anos de idade, dizendo-se orientada por Deus, passou a restringir sua dieta a pão e água, exceto aos domingos, quando comia apenas alguns restos de alimentos deixados na refeição pelas outras irmãs, sempre em pequena quantidade. Forçada a alimentar-se em maior quantidade por suas superioras, passou a provocar o vô- 


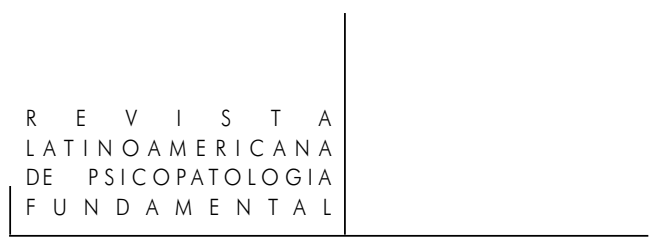

mito, sendo frequentemente surpreendida em outros momentos comendo rapidamente, às escondidas, grandes quantidades de alimento. Para punir-se e prevenir-se das tentações diabólicas açoitava-se, dormia muito pouco - sempre nua sobre troncos de madeira no chão - e banhava-se com água gelada em pleno inverno. Dentre as tentações diabólicas que a atormentavam, figurava um intenso desejo de comer. A vida de santa Maria Madalena foi um suceder de visões de crucificação, uso de coroas de espinhos, sofrimentos físicos autoimpostos e longos jejuns, tudo para cumprir da maneira mais perfeita possível seu destino místico (Bell, 1985). Levando em conta sua resistência a comer, os episódios bulímicos e seu comportamento purgativo, é de se perguntar se um clínico de hoje não lhe daria o diagnóstico de Anorexia Nervosa subtipo purgativo.

Santa Rosa de Lima (1586-1617), ainda criança, passava muitas horas no altar, era escrupulosamente obediente e trabalhadora incansável, dedicando-se com afinco aos afazeres domésticos. Depois de ler sobre a vida de Santa Catarina de Siena tomou-a por modelo, começando por jejuar três vezes por semana e aplicando-se severas penitências. Para não ser tentada pela vaidade, cortou seu formoso cabelo e maltratava suas mãos com trabalhos penosos. Durante dez anos lutou contra o propósito de seus pais de fazê-la casar-se, até que obteve o consentimento para que continuasse em sua vida de devoção a Deus. Aos vinte anos ingressou no convento e reduplicou a severidade e a variedade das penitências. Usava constantemente uma coroa de espinhos de metal, que escondia sob uma fileira de rosas, e uma cinta de ferro na cintura. Podia permanecer dias seguidos sem provar qualquer alimento, salvo um pouco de mel misturado a ervas amargas. Quando já não podia estar em pé, buscava repouso numa cama construída por ela, de vidro picado, pedras e espinhos.

Behar (1991) afirma encontrar evidências de que Santa Rosa de Lima se enquadraria no diagnóstico de Anorexia Nervosa. Em primeiro lugar, pelo seu comportamento alimentar, caracterizado por jejuns frequentes. Em segundo lugar, o que poderia ser tomado como sinal de hiperatividade: diminuição progressiva de sono e aumento das horas de trabalho. Behar aponta ainda para um padrão particular de personalidade, distinguível por sua ambição pelo aperfeiçoamento do espírito, negação de si mesma por meio da autopunição, rigidez, perseverança em seus ideais de santidade, preocupação e dedicação em aliviar os sofrimentos dos outros, além de seu pouco interesse pelos relacionamentos sociais e rejeição ao sexo oposto.

Nascida em uma família católica italiana, Santa Veronica Giuliani (16601727) foi a caçula de sete irmãs. Sua mãe, muito piedosa, sempre atribuía significado religioso a todos os atos da menina, mesmo quando esta era ainda um bebê. 


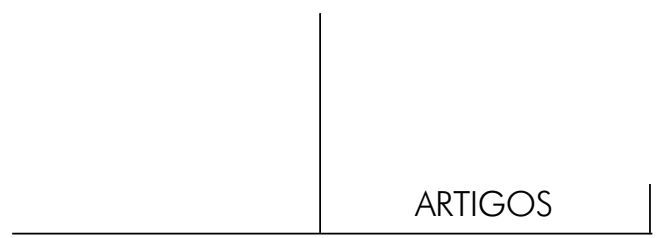

Por exemplo, quando se recusou a ser amamentada, a mãe entendeu que isto acontecia às quartas, sextas ou sábados, dias tradicionais do jejum cristão. Nesses dias, então, a mãe não lhe dava o seio e amamentava uma outra criança necessitada. Influenciada pelas leituras da vida de santos pela família, desde tenra idade procurou imitar Rosa de Lima (que por sua vez imitara Catarina de Siena), submetendo seu corpo a toda sorte de tormentos (Salvatori, 1926). Ao entrar para o claustro, escolheu a ordem dos Capuchinhos, conhecida pelo rigor e disciplina, e adotou o nome de Veronica. Ali, competia com as outras noviças e fazia mais tarefas para provar que amava mais a Deus do que elas. Bell (1985) acredita que este foi o período de sua anorexia, pois segundo os relatos, passava a maior parte do tempo na cela do noviciado ou na enfermaria, onde recebia ordens para mudar sua dieta e quebrar sua rotina de jejum. Quando forçada a comer, vomitava. $\mathrm{Na}$ velhice, mudou seus hábitos e Bell pensa que sua recuperação deveu-se, em parte, ao fato de ela ter vivido num tempo em que esse modelo de ascetismo havia perdido o seu apelo.

O declínio do jejum religioso

Vandereycken e Van Deth (1994) enumeram cinco fatores que teriam levado ao declínio do jejum religioso: a crescente oposição da Igreja Católica Romana ao elevado número de santas jejuadoras e seus imitadores; a mudança no ideal de piedade feminina, com a valorização da caridade, do ensino e da ajuda, em detrimento dos jejuns e autoflagelações; a interpretação dos jejuns autoimpostos como sinais de bruxaria e possessão demoníaca; a valorização do jejum como espetáculo, com as "virgens jejuadoras" (fasting girls ou miraculous maidens), cuja capacidade de viver sem comer era explicada como milagre, e com os artistas da fome que se apresentavam nas feiras; a anexação do jejum prolongado às ciências médicas emergentes, como um sintoma patológico: de virgens miraculosas, as mulheres passaram a ser vistas como pacientes histéricas.

\section{Primeiras descrições da anorexia nervosa}

Em 1691, Richard Morton, médico inglês, publicou a obra Tisiologia sobre a doença da consunção, em que aparece a primeira descrição de quadros que se assemelham à anorexia nervosa contemporânea. A consunção, ou atrofia nervosa, é um definhamento progressivo, caracterizado por três sintomas principais: perda do apetite, amenorréia e emagrecimento importante, com "perda de tecidos corporais". 
A perplexidade de Morton, quando obrigado a lidar com uma paciente que parecia ter escolhido o jejum e que recusava ajuda, abriu espaço para a consideração das bases emocionais do transtorno alimentar (Silverman, 1983).

No ano de 1859, Louis-Victor Marcé apresentou um artigo intitulado "Note sur une forme de délire hypochondriaque consécutive aux dyspepsies et caractérisée principalement par le refus d'aliment", onde afirmava que, apesar da existência de numerosas e variadas formas de dispepsia, algumas chamaram sua atenção pela condição mental peculiar que as caracterizava. A peculiaridade estaria no fato de ocorrer em meninas jovens, no período da puberdade, levando a uma inapetência que poderia chegar a limites extremos. Segundo Marcé, esses distúrbios nervosos eram acompanhados de disfunção menstrual, e as meninas apresentavam uma convicção delirante de que não podiam ou não deviam comer. Essas pacientes, quando orientadas a fazer uma dieta mais suficiente, opunham-se com infinitas estratégias e uma resistência indobrável. Para ele, "estas pacientes não são dispépsicas, mas insanas" (apud Silverman, 1989).

Até as publicações de William Gull, em 1868, a privação de comida estava associada à doença mental ou a doenças orgânicas como tuberculose, diabetes e câncer. A partir dele, a anorexia passou a ser vista como uma patologia independente, cujo diagnóstico implicava em uma aberração moral ou mental enraizada no sistema nervoso, mas exacerbada pela idade da paciente, seu modo de vida, ou ambos (Brumberg, 1989). Inicialmente denominado "apepsia hysteric", o quadro passou a ser chamado de anorexia nervosa quando ele se convenceu de que a "anorexia" (falta de apetite) era um termo melhor do que "apepsia" (indigestão) porque, exceto nos últimos estágios da doença, o alimento podia ser bem digerido.

Para Gull, o diagnóstico de anorexia nervosa podia ser feito tendo por base a severa emaciação, a depressão do pulso e da respiração e a baixa temperatura do corpo. A suspensão da menstruação também seria um sinal da diminuição geral das funções vitais. Sobre o tratamento, Gull recomendava o afastamento da paciente de seu ambiente doméstico e que não fosse consultada sobre o que deveria comer, mas que fosse forçada a isso, para que não se compactuasse com essa "perversão da vontade".

Em um artigo publicado em 1873 intitulado "De l'anorexie hystérique", Charles Lasègue faz um relato detalhado de oito casos de mulheres anoréxicas, descrevendo três etapas dessa patologia. O quadro teria início com uma contrariedade, uma aspiração ou emoção confessada ou dissimulada: a paciente começaria diminuindo sua alimentação e suprimindo sucessivamente a carne, o pão e certos legumes, sem dar sinais de cansaço ou enfraquecimento. Após vários meses, quando o médico, a família e os amigos percebem o quanto seus esforços em alimentá-la são ineficazes, desenha-se a fase essencial da doença, caracterizada por uma "perversão mental", que motiva o nome de anorexia histérica, ca- 


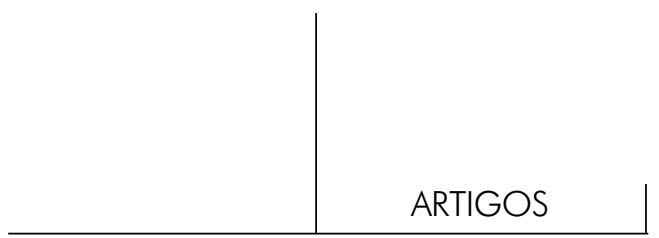

racterizada por uma grande resistência da paciente. No terceiro estágio, as menstruações deixam de ocorrer, a constipação não responde aos purgativos, a pele resseca, aumenta a fraqueza, ocorrem vertigens. Diante da aflição dos familiares, a paciente começa a inquietar-se e pode vir a aceitar o tratamento. Lasègue, com seu artigo, acrescenta comentários preciosos sobre o modo de funcionamento da jovem anoréxica.

\section{Evolução dos conceitos psicodinâmicos}

Até o nascimeno da psiquiatria dinâmica, no fim do século XIX, os médicos estavam presos aos aspectos físicos da anorexia nervosa, ainda que os aspectos emocionais envolvidos na doença já começassem a chamar a atenção. No início da última década do século XIX, praticantes da psiquiatria dinâmica começaram a fazer uso da história de vida do paciente e focar a atenção na descoberta das causas emocionais ou na psicogênese das doenças dos nervos. Entre os praticantes deste novo campo, Sigmund Freud e Pierre Janet tiveram maior impacto no entendimento e tratamento da anorexia nervosa. Embora Freud tenha classificado a doença como uma neurose e Janet a tenha associado a um quadro obsessivo-compulsivo, ambos, cada um à sua maneira, estabeleceram a importante questão conceitual que não havia sido formulada antes: o que a falta de apetite significa?

Assim como Freud, Janet acreditava que o apetite tinha significados simbólicos na psique do sujeito, tendo os dois autores dado origem à ideia psicogenética moderna de que as meninas anoréxicas recusam comida para manter seus corpos pequenos, magros e infantis. Ainda que Freud tenha entendido a anorexia como repugnância pelos alimentos e Janet como recusa, ambos defendiam a ideia de que a falta de apetite constituía uma forma de comportamento simbólico. No entanto, a leitura de Freud da anorexia como um comportamento neurótico que expressa sexualidade não desenvolvida ou reprimida, baseada no seu importante conceito de conversão histérica, distanciou-o de Janet, para quem os comportamentos obsessivos da anoréxica derivavam da "crença de ser feia e ridícula", "não ser como todo mundo" e "não poder ser amada".

$\mathrm{Na}$ atualidade, os textos psicanalíticos (Jeammet, 1994; Bidaud, 1998; Brusset, 1999) chamam a atenção para os laços mais arcaicos estabelecidos entre mãe e filha, articulando o estudo da anorexia ao conceito de narcisismo. Jeammet (1993), um dos autores que tem contribuído significativamente para a compreensão da anorexia na atualidade, acredita que não seria correto associá-la à histeria, como fazia a psicanálise tradicional, mas sim ao narcisismo e às re- 
lações objetais. Segundo esse autor, nenhum tipo de personalidade ou organização psicopatológica pode explicar a gênese do transtorno alimentar, uma vez que a relação que esses sujeitos mantêm com o alimento aponta para um modo de relação de objeto. A anorexia nervosa, como a bulimia, apontariam para uma fragilidade narcísica, um arranjo defensivo em que as relações com os objetos materiais substituem as relações humanas, sentidas como perigosas. Para Jeammet, a dupla antagônica anorexia/bulimia é a expressão mais manifesta de que os transtornos alimentares constituem uma dinâmica específica das relações e dos investimentos, revelando uma relação de tipo passional ou uma atitude de evitamento e retirada dos investimentos.

Numa interface entre a psiquiatria e a psicanálise, situam-se as importantes contribuições de Hilde Bruch para a compreensão da anorexia nervosa: o reconhecimento do papel proeminente da dinâmica familiar na patogenia dessa condição, a relevância dos sentimentos de raiva reprimidos e a negação das necessidades sexuais e do apetite, a incapacidade dos pacientes de controlar elementos importantes de suas próprias vidas, a imagem distorcida do corpo e os benefícios de um tratamento que inclua o indivíduo e a família.

Bruch (1982) observa que as anoréxicas apresentam um comportamento imitativo, que estaria vinculado a déficits básicos do sentido de si mesmo, da identidade e do funcionamento autônomo. A magreza da anoréxica não seria uma expressão de força e independência, mas uma defesa contra o sentimento de não ter uma personalidade própria, de ser fraca e ineficaz. A anoréxica, para Bruch (1978), seria como uma lousa em branco, a ser preenchida com a personalidade de cada nova pessoa com quem se envolve. Tanto que, para essa autora, esse tipo de comportamento imitativo poderia ser o responsável pelo rápido aumento da incidência da anorexia nos últimos anos.

\section{Conclusão}

A presente revisão suscita duas questões importantes: a primeira, se seria apropriado aplicar um conceito psiquiátrico moderno a um quadro descrito no passado e, a segunda, se a anorexia nervosa moderna também teria se modificado.

Liles e Woods (1999) afirmam que grandes similaridades podem ser encontradas entre o meio sociocultural das mulheres que jejuavam e as modernas anoréxicas. Apesar da apresentação do jejum autoimposto ter mudado ao longo dos séculos, a síndrome parece florescer em eras e em sociedades nas quais indivíduos (em geral mulheres) têm falta de atenção adequada, controle e respeito, encontrando na recusa em alimentar-se uma via de expressão. As santas que 
jejuavam eram capazes de sobrepor-se à autoridade religiosa masculina por meio das suas práticas austeras: podiam criticar as poderosas autoridades religiosas seculares e assumir a prática do ensino, aconselhamento ou mesmo reformar, em seu benefício, as regras da Igreja. As meninas jejuadoras do fim da Idade Média recebiam atenção dos padres e dos familiares quando afirmavam não precisar comer devido à divina Providência: elas se assemelhavam de alguma forma às santas medievais, ainda que não fossem recebidas com a mesma veneração e respeito. $\mathrm{Na}$ atualidade, as pressões culturais reforçam o conceito de que ser magra é importante e o apelo da magreza estendeu-se a vários aspectos da vida diária. Em outras palavras, ser magra é ter poder.

Por outro lado, Bruch (1965), Crisp (1967), Russell (1985) e Habermas (1996) afirmam que a distorção da imagem corporal e a fobia de peso, tomadas como critério diagnóstico da anorexia nervosa, impedem que jejuns voluntários do passado e comportamento anoréxico do presente possam ser tomados como quadros semelhantes. De acordo com as pesquisas de Russell (1989), além do aumento da incidência da anorexia nervosa nas últimas décadas, ocorreram também alterações significativas em relação à psicopatologia da doença e mudanças na sua forma, especialmente com a emergência da bulimia nervosa, quadro descrito por ele em 1979. O aumento da incidência teria como explicação as pressões sociais cada vez maiores para que as mulheres tenham um corpo magro, especialmente quando atuam em meninas jovens numa idade em que elas são mais vulneráveis - ou quando as mesmas têm ocupações em áreas onde a forma e tamanho do corpo são enfatizados. O sinal de que houve uma mudança na natureza da psicopatologia central da anorexia nervosa evidencia-se pela preocupação mórbida da anoréxica com seu peso e seu horror a engordar. Outra mudança significativa está na distorção da imagem corporal, mencionada pela primeira vez, por Bruch, em 1962. Russell considera curioso que as observações sobre a distorção da imagem corporal tenham sido feitas apenas nas últimas décadas e se surpreende com o fato de que gerações de médicos capazes não tenham notado características perfeitamente claras da psicopatologia, sendo mais provável que a própria anorexia nervosa tenha mudado em suas manifestações através dos anos.

Além disso, a anorexia nervosa parece ter invadido as camadas economicamente mais desfavorecidas da população. Os dados mostram que, pelo menos no Brasil, cresce o número de pacientes com transtornos alimentares entre a população de baixa renda, inclusive entre meninas de famílias extremamente pobres, que se inspiram nos ideais de beleza das classes mais elevadas (Gonzaga; Weinberg, 2005). Essa observação, que expressa a realidade brasileira, demonstra mais uma vez que a anorexia nervosa mudou, contrariando posições clássicas de que ela teria uma relação direta com riqueza e abundância. A literatura e a observação coincidem, portanto, quando apontam que, em uma parcela de pa- 


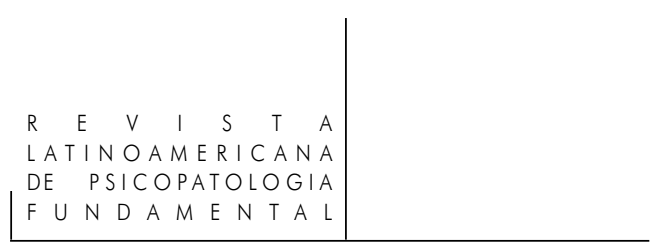

cientes anoréxicos, a sugestão é um fator significativo, o que leva a questionar a eficácia de uma política preventiva, que poderia despertar o interesse pela doença e levar a um resultado indesejado. A implantação de uma política preventiva que promova a qualidade de vida e a aceitação do próprio corpo pode ser mais eficaz porque, ainda que estejam no seu início, os estudos sobre o peso econômico e social (economic and social burden) dos transtornos alimentares, seus custos já começam a ser reconhecidos. Complicações médicas, exames laboratoriais, hospitalização, psicoterapia, medicamentos, exigem grande investimento. Sem contar os danos a longo prazo como osteoporose, infertilidade, cáries dentárias e perda da motilidade intestinal (na bulimia), prejuízos pessoais no trabalho e nos estudos e risco de mortalidade (Crow; Peterson, 2003). Novas áreas, portanto, abrem-se à pesquisa, como, por exemplo, a investigação dos custos na avaliação e tratamento das complicações ou a investigação dos gastos indiretos, ou seja, o impacto da doença nas funções pessoais: abandono dos estudos, prejuízos no trabalho, estudo da perda da qualidade de vida e afastamento do convívio social.

\section{Referências}

Behar, R. Santa Rosa de Lima: un analisis psicosocial de la anorexia nerviosa. Rev Psiquiatria, Chile, n. VIII, p. 707-711, 1991.

Bell, R.M. Holy Anorexia. Chicago: University of Chicago Press, 1985.

Berrios, G. Classifications in psychiatry: a conceptual history. Aust. N Z J Psychiatry, v. 33, n. 2, p. 145-160, 1999.

Bidaud, E. Anorexia mental, ascese, mística. Rio de Janeiro: Companhia de Freud, 1998.

BRuch, H. The golden cage: the enigma of anorexia nervosa. Cambridge: Harvard University Press, 1978.

. Anorexia nervosa: therapy and theory. Am. J. Psychiatry, v. 139, n. 12, p. 1531-1538, 1982.

BRUMBerg, J.J. Fasting girls: the history of anorexia nervosa. New York: Penguin Books, 1989.

Brusset, B. Anorexia mental e bulimia do ponto de vista de sua gênese. In: URRIBARRI, R. (Org.). Anorexia e bulimia. São Paulo: Escuta, 1999.

Cordás, T.A.; Claudino, A.M. Transtornos alimentares: fundamentos históricos. Rev. Bras. Psiquiatr., São Paulo, n. 24 (Supl III), p. 3-6, 2002. 


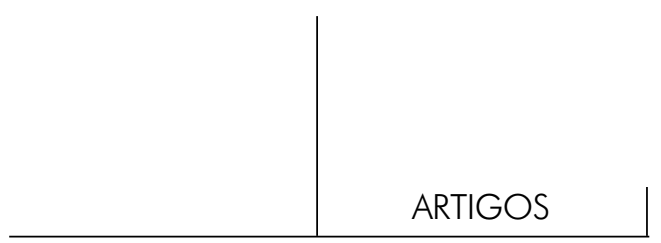

CRISP, A.H. Anorexia nervosa: let me be. London: Academic Press; 1980.

Crow, S.J.; Peterson, C.B. The economic and social burden of eating disorders. In: Maj, M.; Halmi, K.; López-Ibor, J.J.; Sartorius, N. (Eds.). Eating Disorders.

Chichester: Wiley \& Sons, 2003. p. 383-396.

FENDRIK, S. Santa anorexia. Buenos Aires: Corregidor, 1997.

Freud, S. Edição Standard Brasileira das Obras Psicológicas Completas de Sigmund Freud. Rio de Janeiro: Imago, 1997.

Gonzaga, A.P.; Weinberg, C. Transtornos alimentares: uma questão cultural? Revista Latinoamericana de Psicopatologia Fundamental, São Paulo, v. VIII, n. 1, p. V-VI, mar.2005.

HABERMAS, T. In defense of weight phobia as the central organizing motive in anorexia nervosa: historical and cultural arguments for a culture-sensitive psychological concepcion. Int. J. Eat Disord., v. 19, n. 4, p. 317-334, 1996.

JANet, P. Les obsessions et la psychasthénie. Paris: Félix Alcan, 1908.

JEAMmET, P. El abordaje psicoanalítico de los trastornos de las conductas alimentarias. Psicoanalisis con niños y adolescentes, Buenos Aires, n. 6, p. 25-42, 1994.

LACEY, J.M. Anorexia nervosa and a beared female saint. Br. Med. J., n. 285, p. 18161817, 1982.

LasĖgue, C. Da anorexia histérica. Revista Latinoamericana de Psicopatologia Fundamental, v. 1, n. 3, p. 158-171, set.1998.

LiLES, E.G.; Woods, S.C. Anorexia nervosa as viable behavior: extreme self-deprivation in historical context. History of Psychiatry, n. 10, p. 205-225, 1999.

RADI, L. Vida de Clara de Assis. 6. ed. Aparecida: Santuário,1996.

Raimbault, G.; Eliachef, C. Las indomables. Figuras de la anorexia. Buenos Aires: Nueva Visión, 1991.

RusselL,G.F.M. The changing nature of anorexia nervosa: an introduction to the conference. J. Psychiat. Res., v. 19, n. 2/3, p. 101-109, 1985.

Russell, G.F.M.; Treasure, J. The modern history of anorexia nervosa. An interpretation of why the illness has changed. In: The Psychobiology of Human Eating Disorders: Preclinical and Clinical Perspectives. Vol. 575 of the Annals of the New York Academy of Sciences, p. 13-29, 1989.

Salvatori, P.M. Vida de Santa Veronica Juliani. 2. ed. Rio de Janeiro: Padres Capuchinhos, 1926.

Silverman, J.A. Louis-Victor Marcé, 1828-1864: anorexia nervosa's forgotten man. Psychological Medicine, n. 19, p. 833-835, 1989. 


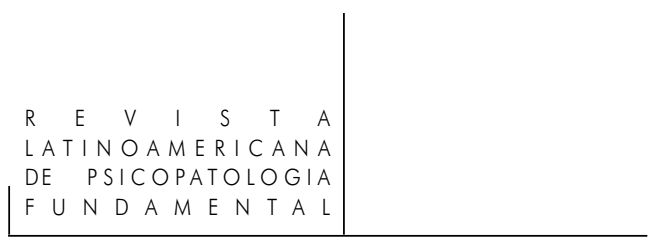

Silverman, J.A. Charcot's comments on the therapeutic role of isolation in the treatment of anorexia nervosa. Eat Disord., n. 21, p. 295-298, 1997.

VAn Deth, R.; VAndereycken, W. Eating disorders. In: A History of Clinical Psychiatry: The Origin and History of Psychiatric Disorders. London: The Athone Press, 1995.

Vandereychen, W.; Van Deth, R. From fasting saints to anorexic girls: the history of self-starvation. New York: University Press; 1994.

\section{Resumos}

(From the ascetic ideal to the esthetic ideal: the historical evolution of anorexia nervosa)

This study of anorexia nervosa from a historical point of view is intended as a contribution to the research on a condition that involves the cultural influence on the origin and maintenance of a clinical reality. The article also questions opinions that consider anorexia nervosa a "modern evil" or the result of a single factor. An analysis of the lives of certain medieval Christian saints, for example, reveals how strongly their persistent behavior, based on asceticism, identifies them with modern anorexic girls, even though, in contrast, their concerns are esthetic

Key words: Holy anorexia, anorexia nervosa, fasting, culture

(De l'idéal ascétique à l'idéal esthétique: l'évolution historique de l'anorexie mentale)

L'étude de l'anorexie mentale à partir d'une perspective historique à comme but de contribuer à l'investigation de ce qui se configure comme influence culturelle sur le développement et le maintien de ce désordre, outre de mettre en question les points de vue selon lesquels l'anorexie mentale serait un "mal moderne", soit le résultat d'un seul facteur. L'analyse de la vie de saintes du Moyen Âge, par exemple, montre que leur conduite persévérante les rapproche des anorexiques modernes, bien que leur motivation et leurs idéaux (ascétisme dans le premier cas, esthétique dans le deuxième) soient entièrement opposés les uns des autres.

Mots clés: Anorexie sainte, anorexie mentale, jeûne, culture

(Del ideal ascético al ideal estético: la evolución histórica de la anorexia nervosa)

El estudio de la anorexia nerviosa desde una perspectiva histórica busca contribuir para la investigación de aquello que se configura como influencia cultural en la génesis y mantenimiento del cuadro, además de cuestionar posiciones según las cuales la anorexia nerviosa seria un "mal de la modernidad" o decurrente de un factor único. Un análisis de la vida de las santas de la edad media, por ejemplo, muestra 


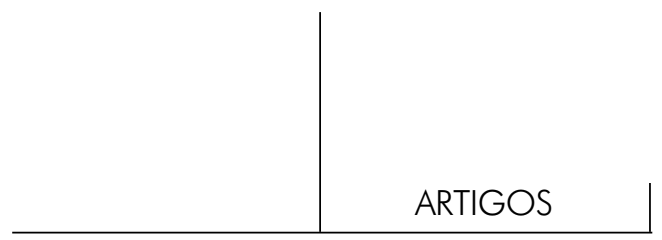

cuanto el comportamiento perseverante las aproxima de las anoréxicas de hoy, a pesar de que la motivación y los ideales (ascético en las primeras y estético en las últimas) sean distintos.

Palabras clave: Anorexia santa, anorexia nerviosa, ayuno, cultura

Citação/Citation: WeinBerg, C. Do ideal ascético ao ideal estético: a evolução histórica da Anorexia Nervosa. Revista Latinoamericana de Psicopatologia Fundamental, São Paulo, v. 13, n. 2, p. 224-237, jun. 2010.

Editor do artigo/Editor: Prof. Dr. Manoel Tosta Berlinck

Recebido/Received: 26.3.2009 / 3.26.2009 Aceito/Accepted: 4.6.2009 / 6.4.2009

Copyright: () 2009 Associação Universitária de Pesquisa em Psicopatologia Fundamental/ University Association for Research in Fundamental Psychopathology. Este é um artigo de livre acesso, que permite uso irrestrito, distribuição e reprodução em qualquer meio, desde que $o$ autor e a fonte sejam citados/This is an open-access article, which permits unrestricted use, distribution, and reproduction in any medium, provided the original author and source are credited.

Financiamento/Funding: A autora declara não ter sido financiada ou apoiada/The author has no support or funding to report.

Conflito de interesses/Conflict of interest: A autora declara que não há conflito de interesses/The author declares that has no conflict of interest.

\section{Cybelle Weinberg}

Psicanalista; Mestre em Ciências pela Faculdade de Medicina da Universidade de São Paulo - FMUSP (São Paulo, SP, Brasil); Coordenadora da Clínica de Estudos e Pesquisa em Psicanálise da Anorexia e Bulimia - CEPPAN (São Paulo, SP, Brasil).

R. João Moura, 627/203 - Jd. Paulista

05412-001 São Paulo, SP, Brasil

Fone: (11) 3081-7778

e-mail: cybellew@uol.com.br

Rev. Latinoam. Psicopat. Fund., São Paulo, v. 13, n. 2, p. 224-237, junho 2010 